\title{
To Revisit Advertising Translation under Nida's Translation Theory
}

\author{
Lu-xin ZHANG \\ School of Foreign Languages, Henan Institute of Engineering, Zhengzhou 450000, \\ China
}

42453091@163.com

Keywords: Advertising language, Functional equivalence, Advertisement translation.

\begin{abstract}
With the rapid development of the global economy, the production of commodities has become extremely prosperous, and the competition has become exceedingly fierce. Therefore, in order to promote sales, manufacturers of each country try their best to set up their images and trademarks of the products through advertising. After a careful study, it concludes that $\mathrm{Nida}$ 's functional equivalence is an effective principle for $\mathrm{C}-\mathrm{E}$ advertisement translation. It also suggests that the translation of advertisement should be "natural", "accurate", and "concise". The theory "content over form" advocated by Nida is mainly for the purpose of solving cultural differences in translation.
\end{abstract}

\section{Introduction}

A number of definitions of advertising exist. Among them there is an authoritative one made by American Marketing Association (AMA), according to the association, advertising is the non-personal communication of information usually paid for and usually persuasive in nature about products, services or ideas by identified sponsors through the various media. Through a careful study of the definition, we may find that advertising bears five important characteristics: (1) Non-personal. Generally speaking, advertising targets not merely one single consumer in particular. (2) There are identified advertisers. The advertisers are the initiators of advertising. All the ads are made for fulfilling the purposes of the advertising. (3) It must be paid. Generally, advertisers have to pay for the ads made for them, because they must purchase time and space for their message in a selected medium. (4) It conveys certain information which is about goods for sales and services provided. (5) Through certain media. All the ads must depend on certain media to reach the target audience.

\section{Classification of Advertising}

With the development of commodity economy and technology, advertising is becoming more and more manifold and complicated in form and category. Advertisements may be classified from various angles. The following are the most common classification of advertising:

(1) Classification by media. Advertising can be divided into newspaper ads, magazine ads, television ads, on-line ads, radio ads, and so on.

(2) Classification by ultimate purposes. All the ads can be divided into two categories: profit-oriented ads and non-commercial ads. The former can further divided into product ads, service ads, corporate ads and idea ads, etc. The former is called product or commercial ads, which aims at making profits by promoting sales and services. Non-commercial ads are usually sponsored by charitable institutions, civic associations, religious or political organizations, with the expectation of 
informing, persuading, or reminding about the particular ideas, causes, or philosophies.

\section{Social Functions and the Creative Principle of Advertising}

In modern life, the influence which advertising has been imposing upon society and economy is so huge that it can never be neglected. The functions of advertising can usually be divided into two types, the social functions and the economic functions. This thesis will focus on the social functions of advertising. It is widely admitted that modern English advertising bears four main social functions:

(1) The function of providing information. Advertising itse lf can bring information of products and services to consumers making them aware of the commodities and services newly provided. Because of this function, ads have offered the customers many opportunities to communicate with the outside world within their limited time and space. Furthermore, ads may influence the consumers to a certain degree of their attitude and behavior during the selection of goods or services. It is quite clear that the informative function of ads has directly or indirectly quickened circulation, enlarged sales, intensified competition, accelerated production and management, and linked up market conditions. In a word, it has developed economy.

(2) The function of persuading consumers. The persuasive function of advertising means that advertising is playing a role of guiding and persuading the target audience while transmitting information.

(3) The function of creating desire. It means that advertising can stimulate demands of the target audience while persuading and guiding them.

(4) The function of reflecting culture. Advertising itself has been creating popularity culture, thus adding flavors to modern urban civilization. Nowadays, with the development of advertising, a new culture —advertising culture, has been shaped.

The above-discussed four functions are the principal social functions of advertising. Generally speaking, one advertisement may embody at least one function, usually two or more.

In order to bring out the subject of an ad. effectively and realize its functions, certain creative principle must be followed. The principle AIDMA is a classical creative principle most acceptable in ad. writing. AIDMA is the abbreviation of the following words: (1) A: Attention-attract attention: (2) I: Interest---arouse interest (3) D: Desire---create desire (4) M: Memory--- leave memory (5) A: Action.

To put them in one sentence, a successful ad. must be able to attract attention, arouse interest, stimulate desire of the target audience, leave memory to them and get them into action. To achieve this goal, first important of all, the language of an ad. must be eye-catching, as well as readable. With simple language, ads can make the message-transmitting more easy and rapid. Occasionally, in order to attract the audience, novel words, such as coined, misspelling or loaned ones are frequently used.

\section{Main Stylistic Features of English Advertising}

Words and phrases employed in advertising are mainly simple, colloquial and monosyllabic. What's more, slang, coinages and compound words are occasionally employed to make the ads seem different and appealing. Adjectives and verbs used in ads have some unique features. Firstly, most commonly used adjectives are decorative or evaluative to arouse sympathetic responses of the consumers, such as big, good, fresh, true, fabulous, inexpensive, etc. Secondly, the comparative and superlative 
degrees of adjectives appear frequently in ads, indicating that the products or services advertised are better or the best.

Simple and monosyllabic verbs appear frequently to make ads. more readable, for example, the verb buy is often used instead of purchase, make rather than manufacture. Only through this can ads meet the need of different consumers, make them easier to understand and remember. Moreover, short and simple ads can reduce the expense on the ads. More messages can be transmitted by fewer words.

The whole ad. consists of only three commonly used words, but the aim of the ad. has been completely achieved by thrifty language. It can make important message outstanding. Also, it helps to save money through saving space. The colloquialism of advertising language demands the use of imperative and interrogative sentence, because the former bears the functions of arousing and urging readers and the latter can arouse attention and curiosity of the audience.

\section{Rhetorical Devices of Englis h Advertising}

Rhetorical device is an effective technique of expressing exactly, vividly and impressively. Advertising, in essence, is a communication. No matter what form it may be, advertising must rely on certain language to bring out its subject, bid ideas, transmit information and promote sales. Anyhow, the target audiences are not always ready to accept any ads. On most occasions, they hold a passive, picky and even repellent attitude toward them. Under this circumstance, the employment of appropriate words to make the ads more acceptable and convincing, thus creating desire and realizing sales has become rather necessary. To achieve this purpose, copywriters have to resort to rhetorical devices, which can make the ads more vivid, elegant, charming and persuasive. Simile, metaphor, pun, euphemism, hyperbole, metonymy, synecdoche, repetition, personification and rhyming are the most frequently employed rhetorical devices in ads.

China has a history of translation for about as long as 2000 years. During the long time, there have emerged a large number of incisive ideas on literary translation. Yan Fu (A.D. 1854-1921), a famous scholar of the late Qing Dynasty (A.D. 1644-1911), who had synthesized all the important ancient Chinese translation thoughts, and summarized the essence of the thoughts into a three-character criterion: "faithfulness, expressiveness, and elegance." Yan Fu's theory was the heritage and development of Chinese translation theories and had added an illustrious page to the annals of Chinese translation study. However, once it is applied to the translation of non-literary writings, such as ads, Yan Fu's criterion may lose its effect. The problem lays in the word "elegance" of the principle. By elegance, Yan Fu held that only the language before the Han Dynasty (before A.D 220) could be considered elegant and old vocabulary, old structure of Chinese must be used in order to represent the original fully and adequately. Therefore, Yan Fu can be said to object to the use of the vernacular or popular language of the people. However, as mentioned before, one of the major features of advertising language is the employment of colloquial, popular words or even slang. Then, how must a transla tor use elegant language to translate the ads written in popular, colloquial words? If one insists, then he or she will ruin his or her translation by merely adding difficulty to the understanding of the readers, and hinder the information from being trans lated rapidly and effectively. 


\section{Conclusion}

Making a general survey of Catford's theory, we may find out that the basic prerequisite needed by his equivalents mechanism is to replace grammar and vocabulary of the source language by their equivalence in the target language. That's to say, only when there exists these equivalents in both languages, can the "equivalence" be acquired. Yet due to differences between the two cultures, histories and psychologies, different languages, especially languages of different families do have huge differences in structures, backgrounds, and patterns. Therefore, it is impossible to accomplish structural and semantic equivalence between two languages of the family. Moreover, "textual equivalence" is a typical "text-centered" translation mode, which does not fit for ads. translation and this will be discussed in the following parts.

\section{References}

[1] Bobee, C \& Arens, W. Contemporary Advertising [M]. U.S.A: IRWIN, 1989, 67-98.

[2] Muller, Barbara. International advertising: Communicating Across Culture [M]. USA: Wadsworth Publishing Company, A Division of International Thomson Publishing Inc, 1998, 113-165.

[3] Nida, Eugene A. Toward a Science of Translating [M]. Leiden: E.J, 1964, 69-146. 